MANDINGA, TERA DECORAÇÃO, MÚSICA, UTILII DOMÉSTICAS E ESCÁ OS DIVERSOS DOS CH 


\section{MANDINGA, TERAPIA, DECORAÇÃO, MÚSICA, UTILIDADES DOMÉSTICAS E ESCÁRNIO: OS DIVERSOS USOS DOS CHIFRES}




\title{
MANDINGA, TERAPIA, DECORAÇÃO, MÚSICA, UTILIDADES DOMÉSTICAS E ESCÁRNIO: OS DIVERSOS USOS DOS CHIFRES
}

\section{Resumo}

Este ensaio lista, descreve e analisa os usos de chifres de bovinos tanto do ponto de vista material, quanto imaterial, revisitando a literatura sobre o assunto e pontos do Estado do Pará em que os mesmos se encontram à venda ou em exposição, indicando os diversos tipos de demanda existente para este tipo de produto. O primeiro destes pontos é a Feira do Ver-o-Peso, em Belém, entreposto comercial que concentra saberes e costumes de parte da Amazônia, por se encontrar na capital do Estado, em pleno delta do rio Amazonas. O outro ponto se encontra no Nordeste Paraense, à beira da Rodovia Estadual Governador Fernando Guillon - PA 124, no município de Santarém Novo, a 168 km de Belém. Neste se encontra uma barraca com sortimento de chifres de bovinos pintados e em exposição na beira da estrada, cujo dono é informante desta pesquisa. Finalmente, leitura pertinente ao assunto e observação direta são as fontes dos usos que se faz desta extremidade dos bovídeos em magia, terapia, decoração, música, escárnio e utensílios domésticos.

Palavras-chave: Religiosidade, bruxaria, magia, utensílios domésticos, estética, semiótica.

\section{MANDINGA, THERAPY, DECORATION, MUSIC, HOUSE WARES AND DERISION: THE VARIOUS USES OF HORNS}

\begin{abstract}
This essay lists, describes and analyzes bovine horns both in terms of material and immaterial use, revisiting the literature on the subject and areas of state of Pará, Northern Brazil, in which they are offered for sale or exhibition, indicating the various types of existing demand for this type of product. The first of these locations is the Ver-o-Peso Market, in Belém, Brazil, commercial hub that concentrates knowledge and customs of the Amazon, for being in the state capital, overlooking the delta of the Amazon River. The other location is the Northeastern portion of the state, along the State Highway Governor Fernando Guillon - PA 124, in the municipality of Santarém Novo, $168 \mathrm{~km}$ northeast of Belém. There we can find a stand with a variety of bovine horns painted and exhibited at the roadside, whose owner is the informant of this research. Finally, relevant subject reading and direct observation are the sources of usage that makes this bovine end in spells, therapy, decoration, music, derision and house wares.
\end{abstract}

Keywords: Religiosity, witchcraft, magic, house ware, aesthetics, semiotics. 


\section{SOURCELLERIE, THERAPEUTIQUE, DECORATION, MUSIQUE, OUTILS DOMESTIQUES ET DERISION: LES PLUSIEURS USAGES DES CORNES}

\section{Résumé}

Cet essai présent une list, description et analyse des usages des cornes de bovins du point du vie matériel aussi que imatériel. Il met en rapport la litérature scientifique et des observations faites sur des points commerciaux de l'Étatu du Pará où ces produits se trouvent à vente ou en exposition, ce qui indique la démande qui existe pour ce genre de produit. Le premier de ces points est le Marché Ver o peso, en Belém, entrepôt commercial qui concentre des savoirs et des usages des peuples de l'Amazonie pour se trouver dans la capitale de l'État, juste dans l'embouchure de l'Amazone. L'autre point se trouve au Nord Est du l'Etat du Pará, au bord de la Route de l'Etat Governeur Fernando Guillon - PA 124, dans la municipalité Santarém Novo, à 168 km de Belém. Lá se trouve une boutique avec une varieté de corns de bovin peintre et en exposition au bord de la route, dont le proprietaire est un des enquetés de cette recherche. Finalement, des lectures sur le sujet et l'observation directe ont été les sources qui ont permu écrire sur les usages qui se font des extremités des bovins pour la sourcellerie, la thérapeutique, la décoration, la musique, la dérision et les outils domestiques.

Mots-clés : Religiosité, sourcellerie, magie, outils domestiques, estétique, semióptique.

Endereço do autor para correspondência: NCADR - Universidade Federal do Pará, Rua Augusto Corrêa, No 1, Cidade Universitária José da Silveira Neto, Guamá, CEP: 66075-110, Belém, PA, Brasil 


\section{CHIFRES E CORNOS}

A palavra chifre vem do "espanhol antigo chifle, derivado do verbo chiflar" (Ferreira 2000: 386), que significa assobiar. O termo corno deriva do latim cornu, significando o "apêndice duro e recurvo que guarnece a fronte de alguns animais" (Ferreira 2000: 386; Cunha 2010: 181). Os chifres e cornos se diferenciam pela origem anatômica de cada um deles. Os chifres derivam de estruturas ósseas e são comuns aos machos na família dos cervídeos (cervos e veados). Os cornos se originam do tecido epitelial e são comuns aos bovídeos (boi, cabra, rinoceronte, búfalo, gnu, bisão, impala). Em que pese esta diferença estrutural, ambos são chamados popular e genericamente de chifres, o que nos faz adotar esta terminologia para este ensaio que analisa a apropriação destas partes dos animais em usos materiais e imateriais em diversos países e culturas do planeta.

\section{O CHIFRE NAS RELIGIÕES}

A apropriação de elementos da natureza na representação de personagens religiosos é fartamente documentada em livros sagrados, documentos, narrativas orais e escritas que atravessam a história da humanidade. Estas narrativas e documentos refletem a concepção da relação do homem com a natureza, seja atribuindo-se ao homem o estatuto de ser vivo como outro qualquer, passível de se misturar com animais ou com deuses, como na mitologia grega, seja projetando-lhe como ser superior à natureza, como na cultura judaico-cristã (Porto-Gonçalves 2005: 32). É neste contexto que podemos encontrar figuras resultantes da primeira concepção, como o centauro e o minotauro, em que se projeta a força e a virilidade, sejam nas figuras angelicais e diabólicas das religiões tanto pagãs quanto nas monoteístas e politeístas. Em todos os casos, as representações absorvem elementos constitutivos dos animais para simbolizar virtudes ou defeitos. Se nos anjos, as asas são um atributo que se incorpora para demonstrar agilidade no deslocamento espacial, os chifres, nos demônios, assumiram um caráter distintivo de maldade, embora nem sempre tenha sido esta a representação desta parte dos bovídeos na iconografia ao longo da história da humanidade.

Não só de bovinos são os chifres utilizados como utensílios para funções religiosas. Segundo Bruce-Mitford (2001: 16) no judaísmo, o toque do shofar, instrumento feito de chifre de carneiro, anuncia o ano novo judaico (Rosh Hashana). O seu toque conclama ao arrependimento dos pecados e evoca a oferenda de Deus a Abrahão para substituir o filho Isaac que teria sido sacrificado por solicitação do mesmo Deus (Bruce-Mitford 2001: 16).

A representação dos chifres de bovinos aparece tanto no hinduísmo (BruceMitford 2001: 16, 21), como no gesto europeu contemporâneo fechando-se os dedos anelar e médio, deixando em posição vertical o indicador e o mindinho, atribuindo-se a este os poderes para afastar o azar (Idem: 118). 
Usando as mãos fechadas, postas à cabeça, com os indicadores apontando para cima, imitando os chifres, este gesto pode significar, em países latinos, pessoas traídas e no Japão uma mulher zangada ou com ciúmes (Bruce-Mitford 2001: 118).

$\mathrm{Na}$ mitologia grega é conhecida a estória do minotauro, personagem que teria metade de touro e metade de homem, com representações diversas, entre as quais uma com tronco e membros de humano e cabeça de bovino. A ele se atribuía força e brutalidade que deveriam ser aplacadas anualmente com a oferta de carne humana de sete moças e sete rapazes. $\mathrm{O}$ reinado de terror se encerra com a vitória do ateniense Teseu sobre este ser mitológico que habitava um labirinto da Ilha de Creta (Idem: 28). Teria nascido de uma união espúria entre Pasifae, esposa de Minos, e um touro criado no palácio daquele rei.

Pode-se encontrar em representações pictóricas os cornos de caprinos como símbolos do amor e da sexualidade (Ronecker 1997: 296), o que por repressão das religiões teria transportado esta qualidade para a representação do mal em muitas das figuras exotéricas que se podem encontrar na iconografia de confissões religiosas, seitas e mandingas praticadas popularmente.

Na Igreja de Nosso Senhor do Bonfim, em Salvador, na Bahia, Brasil, dois quadros representando as mortes do justo e do pecador trazem demônios com chifres. Conforme demonstra Sant'Anna (2006: 63 e 64), este mesmo tema é representado em igrejas e museus mineiros, com os demônios aparecendo com representações em que os cornos são uma marca registrada de sua identificação (Figura 1).

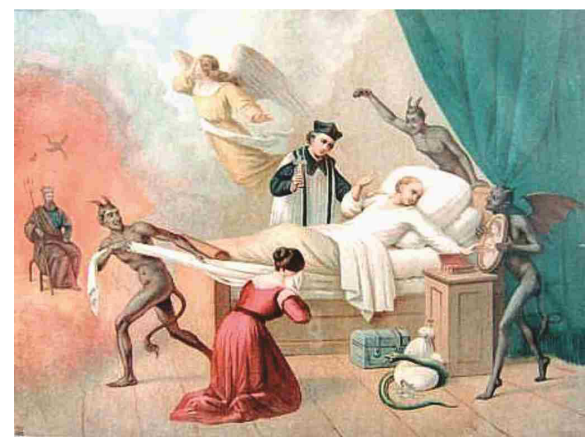

Figura 1 - A morte do pecador. Fonte: Litogravura, acervo do Museu Regional Casa dos Otoni, Serro (Brasil), século XX. Foto: Júlio Martins. Sant'Ana (2006: 78).

$\mathrm{Na}$ linguagem popular, como expressa a letra da música de Dudu Nobre (2012), compositor carioca consagrado, os chifres do bode estão associados à bruxaria.

Eu vou botar o teu retrato num prato com pimenta

Quero ver se você [a]guenta a mandinga que eu vou te jogar

Raspa de chifre de bode, pedaço de rabo de jumento

Tu vais botar fogo pela venta e comigo não vai mais brincar.

O mesmo sentido de associação do bode com a feitiçaria é referido por Ronecker (1996: 296), reportando-se a histórias registradas na Europa, sendo uma história com origem no século XII, na Dinamarca, narradas por Saxo-Gramaticus e Robert Graves, evocando tradições em que o bode é montaria de bruxas e deusas, associado à lubricidade, sexualidade e fecundidade.

Os chifres representam a maldade na magia, mas como demonstrado no Quadro 1 pode-se encontrar sua representação com outros significados em diferentes civilizações humanas. 
Quadro 1

Representação dos chifres nas diversas culturas e país

\begin{tabular}{|l|l|}
\hline Representação & Culturas/países \\
\hline Ciúmes & Japão \\
\hline Poder, força, agressividade, virilidade & $\begin{array}{l}\text { África, Judaísmo, Cristianismo, Índia, } \\
\text { Celtas, Egito, Itália, China, País de Gales, } \\
\text { Macedônia, Iroquês, Sibéria, Peul, Tunguses, } \\
\text { Samoiedes, Ienisseienses }\end{array}$ \\
\hline Caráter solar & Macedônia \\
\hline Caráter lunar & $\begin{array}{l}\text { Sumérios, Pérsia, Índia, Judaísmo, Cris- } \\
\text { tianismo, Cambodja, Dogons, }\end{array}$ \\
\hline Fertilidade/Fecundidade, Abundância & Neolítico, Dogons, Grécia \\
\hline Braços transversais da cruz & Cristianismo \\
\hline Força regressiva, Ambivalência & Contemporaneidade, Irlanda, Índia védica \\
\hline Capacidade de trabalho e sacrifício & Boi (Judaísmo) \\
\hline Comunicação com o divino & Judaísmo, Cristianismo \\
\hline Masculino (exterior do chifre) & Celtas \\
\hline Feminino (interior do chifre) & Celtas \\
\hline Morte violenta & Celtas e Gauleses \\
\hline
\end{tabular}

Fontes: Chevalier \& Gheerbrant (2012); Ronecker (1996); Bruce-Mitford (2001).

No Quadro 1, a representação dos chifres transmitem por esta extremidade do animal significados a eles atribuídos nas diversas culturas e partes do mundo, com interpretações diversas, convergentes ou divergentes, ora indicando poderes, ora fragilidades, ora beleza, ora terror. Existem significados que são dados pelo animal portador do chifre, em outros pelo chifre representando o animal como um todo, mas no caso do quadro acima foram listados o que se expressa pela extremidade mesma do chifre, em que pese poder haver confusão entre um e outro por conta da alusão feita ao todo pela parte. Chevalier e Gheerbrant referem que há uma inscrição no Camboja que menciona a lua como um chifre perfeito, relatando o aspecto chifrudo do touro de Xiva. Segundo estes mesmos autores, citando Bhab, Grac e Gues, está escrito no Mahâbhârata, o livro sagrado do hinduísmo, a referência ao chifre de Xiva por que esta se identifica com a sua montaria (Chevalier \& Gheerbrant 2012: 234).

\section{O SIMBOLISMO DO CHIFRE}

Ao contrário do que se pode constatar na reação de imediata hilaridade das pessoas quando se fala em chifres, tanto Chevalier \& Gheerbrant (2012: 233-235) quanto Ronecker (1996: 290) se referem a eles como símbolo de eminência, de elevação e de poder, afirmando encontrar seu uso simbólico praticado entre gregos, egípcios, su- 
merianos, chineses, siberianos, romanos, gauleses e celtas. A associação do caráter do chifre bovino com a lua era reconhecida entre sumerianos e hindus (Chevalier \& Gheerbrant 2012: 234; Bruce-Mitford 2001: 61), o que é perfeitamente compreensível se considerado o seu formato no período de quarto crescente, conforme explicam os autores e demonstra a (Figura 2), apresentada por Bruce-Mitford (op. cit.).

A identificação do chifre com o quarto crescente remete a significados positivos e também podem ser encontrados na iconografia cristã. É comum a representação da concepção de Maria com a imagem de uma mulher sobre uma lua em quarto crescente, que evoca a feminilidade e a fecundidade.

Os mesmos autores atribuem caráter solar aos chifres de carneiro, deixando a interpretação em aberto (Chevalier \& Gheerbrant 2012: 234), entretanto Ronecker (1996: 295) refere que é freqüente atribuir-se aos caprinos o caráter lunar. Para Chevalier \& Gheerbrant os chifres estão associados des-

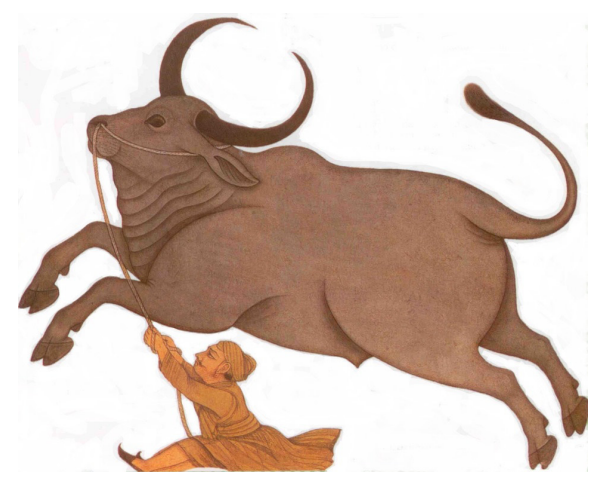

Figura 2 - Representação do boi em miniatura chinesa do século XVIII. Fonte: (Bruce-Mitford 2001: 61). de o neolítico à fertilidade tendo sido usado na representação da natureza divina do poderio e genio de Dionisio e Alexandre, o Grande. Ora está associado à feminilidade, pela fecundidade, maternidade, fertilidade, ora à masculinidade, em contextos históricos diferenciados, significando agressividade, poder e virilidade (Chevalier \& Gheerbrant 2012: 234).

Raios e chifres estão interligados na cultura judaico-cristã, de tal forma que Moisés é representado em imagens medievais com chifres em formato de lua crescente, ao descer da montanha. Uma das representações mais famosas deste personagem se encontra em Roma, na escultura de Michelangelo representando Moisés (Figura 3). Os chifres teriam se originado em um erro de tradução de São Jerônimo que interpretou qaran (resplendor) como queren (chifres) (Câmara 2011). Há versões que dizem ter a palavra hebraica queren tanto o significado de chifre como de raio (Chevalier \& Gheerbrant 2012: 234). As referências ao Moisés de Michelangelo são muitas e Mariguela (2010) faz uma análise em que o motivo da admiração de Sigmund Freud pela estátua se acentua justamente em um momento que pode ser interpretado como de traição de Jung aos desejos de Freud que pretendia tê-lo como herdeiro da psicanálise (Mariguela, 2010). Para usar o mesmo Freud, conscientemente ou inconscientemente, a interpretação de traição e tradução se confunde, tanto quanto a de fidelidade.

Segundo Chevalier \& Gheerbrant, encontram-se referências aos chifres nos salmos (18, versículo 4; 75, versículo 6 e 132, versí- 


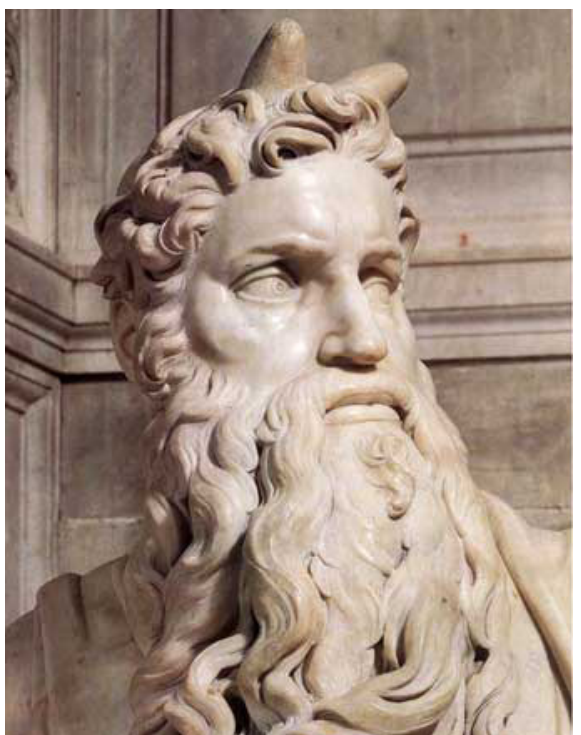

Figura 3 - Moisés de Michelângelo, na Igreja de São Pedro in vincoli, em Roma. Fonte: Mariguela (2010).

culo 17) simbolizando o poder de Deus, ou a força arrogante e agressiva dos soberbos, ou a força, simplesmente. O que se verifica, entretanto, na tradução ecumênica destes mesmos salmos (Bíblia 1995), é que a palavra chifre vem sendo substituída por "citadela", no salmo 18, por "fronte", no salmo 35 e por "vigor", no salmo 132, indicando que a tradução literal desvirtuava o sentido simbólico que é dado à palavra chifre em cada um daqueles salmos. Sua ambivalência, ainda segundo Chevalier \& Gheerbrant, é representada pelas associações com o sol e a lua, mas também com o poder de Deus e o do diabo (op. cit.: 235).

A cornucópia, chifre invertido e utilizado como receptáculo, aparece na tradição greco-romana como símbolo de fecundidade e felicidade (Chevalier \& Gheerbrant 2012: 288).
Longa e oca, a cornucópia pode ser uma representação feminina ou masculina, segundo Bruce-Mitford (2001: 71). Segundo Ronecker (1996: 291), para os celtas a parte interna do chifre representa a feminilidade por associação com a vagina, receptáculo da vida para a criação no interior da matriz. A parte externa, para esta mesma cultura, pela sua dureza e forma, representa o falo humano, ereto, "prestes a ejacular o esperma que dá a vida" (op.cit.). Estas associações com culturas pagãs expressando sentimentos carnais permitem a interpretação de que nas religiões puritanas tenham levado à representação de maldade, impureza e pecado e, portanto, associada ao diabo.

\section{O CHIFRE NA LEI OU A LEI DO CHIFRE}

O aspecto jocoso que se faz do chifre tem expressão na cultura latina, particularmente no Código Filipino português que impunha o açoite ao homem que aceitasse $\mathrm{o}$ adultério, sendo a pena cumprida com o uso de uma grinalda de cornos. ${ }^{1}$

“9. E sendo provado, que algum homem consentiu à sua mulher (1) que lhe fizesse adultério, serão elle e Ella açoutados com senhas capellas de cornos (2), e degradados para o Brazil, e o degradado será degradado para sempre para África, sem embargo de o marido thes querer perdoar (3)".

O que explica as chamadas (1) é que a acusação é negada aos culpados e não pune o marido. A chamada 2 se refere à explicação do termo "senhas" que deve ser traduzido como "suas", sig- 
nificando que cada um dos condenados deve portar a sua grinalda de cornos. A nota três faz referência a uma citação de Barbosa, que relata como se fazia a punição destes casos na Alemanha (Código Filipino 1870).

“... o marido era castigado com açoutes, ou montado em um asno com a face voltada para o rabo do animal, o qual era conduzido pela mulher, dizendo um Pregoeiro: qui sic faciet, sic copist. Quem assim procede, he desta forma compensado."

Em artigo sobre o tratamento dado nestes casos, Toma explica:

"Capela de cornos era uma espécie de grinalda de cornos que deveria ser utilizada quando o marido consentisse o adultério de sua esposa. A legislação mandava que tanto o marido quanto a esposa se apresentassem vestidos com a indumentária para os açoites públicos que precediam o degredo para o Brasil. Ver Ordenações filipinas, Livro V, Título 25, §9.” (Toma 2005: 23).

Em desuso a prática da punição aos que infringissem as regras e costumes da fidelidade, manteve-se o caráter jocoso e agressivo aos traídos, o que no Brasil, em contextos diferenciados, se expressa de uma forma ou de outra.

\section{OS DIVERSOS USOS DO CHIFRE}

Há um ditado popular brasileiro que reza: "do boi só se perde o berro", como registrou Ednardo em uma de suas canções. ${ }^{2}$ Com as novas tecnologias e a inventividade humana, nem este se perde mais, uma vez que sua utilização na música, nos aboios e nas buzinas de automóveis tem sido uma constante do mundo contemporâneo. Os vaqueiros brasileiros usam o chifre do boi como instrumento musical, tangendo boiadas e sinalizando sua passagem pelos caminhos que percorrem. No caso desta atividade dos tropeiros, o berrante incorporou-se como um símbolo que aproxima homens e bovinos pelo sopro e sonoridade que este lhe provoca.

Como ponto de partida teórico, a diversidade de usos, de olhares e interpretações possíveis para um mesmo objeto, evoca o conceito desenvolvido por João de Jesus Paes Loureiro (1995: 39) de conversão semiótica. Segundo ele “a conversão semiótica significa o quiasmo de mudança de qualidade simbólica em uma relação cultural, no momento em que ocorre essa transfiguração". Neste sentido, o chifre pode ser um elemento estético utilizado para decoração, religioso como um amuleto, ou um utensílio como um copo, a depender da perspectiva de quem lhe faz uso, de quem lhe interpreta, ou do contexto em que se situa o objeto.

Às margens da Rodovia Estadual Governador Fernando Guilhon, PA 124, que dá acesso ao nordeste paraense, no $\mathrm{km} \mathrm{49}$, onde se situa o distrito de Jutaí Grande, no município de Santarém Novo, estão expostos em uma barraca dezenas de chifres de bovinos polidos, pintados de cores constrastantes (preto, branco, azul, vermelho, roxo) e dispostos como atrativo. A exposição destes objetos chama a atenção pela variedade e pela originalidade com que são mostrados, pendurados nas estruturas da varanda do bar. Foi a obser- 
vação do apresentado neste local que inspirou a construção deste ensaio, ao projetar com intensidade e visibilidade incomum este tipo de objeto que usualmente provoca hilariedade ou temor pelos usos mágicos que dele se possa fazer.

O dono do ponto comercial, $\mathrm{LFD}^{3} 53$ anos (2012), ${ }^{4}$ natural daquela mesma localidade, relata, com desembaraço, os usos que os seus compradores evocam para a compra do material.

"Quem mais compra é o pessoal que tem comércio. Dizem que é para afastar mal olhado, olho gordo! Outros dizem que é para fazer brincadeiras com amigos que tem mulheres bonitas e que podem estar traindo o sujeito! Mas eu vendo também estes que servem para copos, para beber cerveja."

Todos os chifres expostos pelo senhor LFD estavam polidos e pintados de cores diversas, conforme se pode ver na (Figura 4). Indagado sobre se tinha daquele material bruto, sem nenhum tratamento estético, ele disse que tinha para venda e foi buscar um saco de rá-

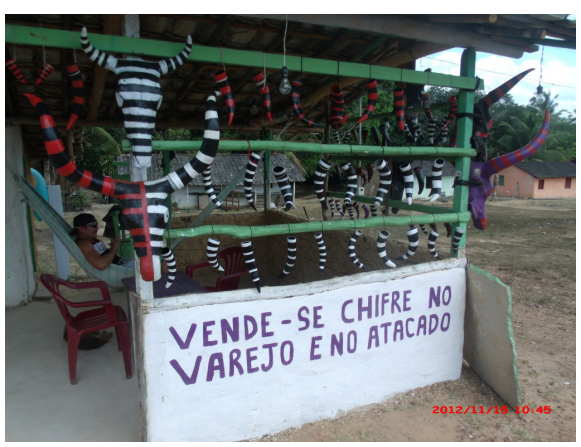

Figura 4 - Exposição de chifres ornamentais na barraca do Louro, em Jutaí Grande, Santarém Novo, Pará. Foto: Gutemberg Guerra. Jutaí Grande, novembro de 2012. fia com em torno de vinte deles. Sem acabamento, os chifres são pouco atraentes, mas ele afirma que são vendidos assim mesmo, para serem queimados sob a alegação de que repelem insetos e afasta olho gordo.

Indagado sobre a aquisição dos chifres, disse estar em uma região de fazendas, em que é comum o abate de bovinos. Os chifres são dados para quem lhes queira, uma vez que não estão na atividade fim das fazendas nem dos comerciantes de carne. A matéria prima é, portanto, de fácil aquisição e paga com doses de aguardente para os funcionários dos matadouros ou das fazendas que lhe trazem este material.

Em se tratando do aspecto estético, fez uma exposição sobre os procedimentos para transformar as peças originais em peças ornamentais. Lixar para eliminar irregularidades, pintar e polir são operações que custariam, segundo ele, certo tempo, sem especificar quanto. Ao insistir na pergunta, tornou-se evasivo atribuindo ao tamanho e estado da peça a variação do tempo para seu tratamento, não excedendo, cada uma delas, mais do que quatro horas para lixar, extrair e eliminar resíduos em decomposição e pintar. Este trabalho de natureza estética valoriza as peças, e justifica o investimento pelo melhor preço que pode obter em cada unidade.

As pinturas encontradas foram em listras em preto e branco, vermelho e preto ou simplesmente todo em preto ou todo em lilás. Embora não estivessem gravados os escudos, tampouco fosse feita alusão pelo vendedor, as cores lembram as de clubes de fute- 
bol conhecidos no país. O Sr. Lourival referiu que tem aumentado a demanda por pinturas com as cores de clubes do Estado do Pará, em particular das duas maiores torcidas (Remo e Paysandu), embora ele se mantenha neutro em relação a estes pedidos. Quanto ao lilás, deu uma resposta evasiva, de estar aproveitando uma tinta da qual dispunha, sem revelar uma intenção que pudesse ser associada a algum motivo específico.

Em fevereiro de 2013, foram apresentados em exposição chifres grandes, com pinturas de flores. Perguntado sobre aquela nova estética, LFD respondeu que se tratava de trabalho de uma senhora que utilizava tinta de pintar tecido e que deixara as peças em sua barraca, para vender. Eram dois chifres de Guzerá (Bos indicus), pintados de preto e sobre esta base, temas florais, conforme Figura 5.

A defumação feita com os chifres produz fumaça de odor característico, acentuado, repelindo insetos e roedores que estejam abrigados nas frestas das casas, armazéns e celeiros. É esta característica de cheiro incômodo a que se atribuem poderes de espantar animais peçonhen-

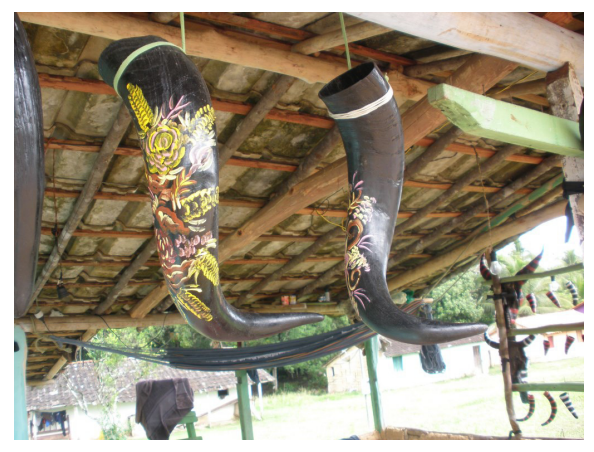

Figura 5 - Cornucópias com temas florais. Foto Gutemberg Guerra, fevereiro de 2013. tos e seres malignos das habitações e dos campos onde é utilizado.

Os chifres vendidos em Jutaí Grande eram ocos ou parcialmente preenchidos com material que o Sr. LFD afirma ser do próprio animal. Todos estavam expostos de ponta cabeça, amarrados com um cordão negro e quatro de cinco deles adquiridos aleatoriamente não se conseguiam equilibrar em uma superfície plana.

Havia expostos na área de venda do bar, esqueletos de cabeças inteiras de bovinos pintados de cores diversas. Para estas peças o senhor LFD explicou como sendo adquiridas para ornamentar porteiras de fazendas, chácaras e sítios com a mesma finalidade de afastar olhares malévolos.

Em viagem feita pela área de influência da Barragem de Belo Monte, em execução, registrou-se o esqueleto de uma cabeça de bovino, sem pintura, enfiada em uma estaca próxima à porteira. Indagado sobre o significado daquela alegoria, o habitante da casa, vaqueiro, respondeu que se tratava de resto mortal de um animal querido do fazendeiro, e que o mesmo resolveu expor naquele local como lembrança afetiva do bovino.

Este uso tosco, sem acabamento de partes dos animais tem seu contraponto na refinada indústria de moveis da qual podemos encontrar pistas nos sites de busca em que se apresenta tanto a demanda por matéria prima como a oferta de móveis acabados. No caso da demanda, pode-se encontrar o seguinte anúncio:

"Tem um tipo de Mamute Enfurecido da Planície de Gelo na Tundra 


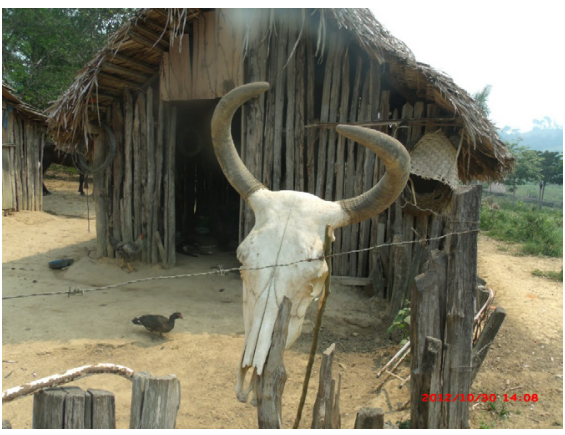

Figura 6 - Cabeça de vaca em lote na zona rural em Pacajá, Pará, outubro de 2012. Foto: Gutemberg Guerra.

Fiergen. Eu preciso do Chifre Afiado da cabeça dele para fazer arte e artesanato. Qualquer um que esteja disposto pode vir e me ajudar.

Preciso de 18 Chifre (sic) Afiado das cabeças de Mamute Enfurecido da Planície de Gelo."

No caso acima a referência é o animal selvagem, vivendo em clima inóspito, indicando a dificuldade na sua obtenção, mas subliminarmente apelando para a dureza e rusticidade do animal o que certamente implica em majoração do valor a ser comercializado.

No caso da oferta de móveis acabados tendo como matéria-prima chifres bovinos, apresentam-se modelos com desenhos elaborados, em que partes de chifres transformados em pastilhas são utilizadas para compor as estampas, conforme indicado na figura 7 .

O que se pode deduzir é que se ampliam as possibilidades de uso deste material comum em outros artefatos como cabos de instrumentos domésticos (talheres, armas, facões) para a incrustação em móveis refinados.

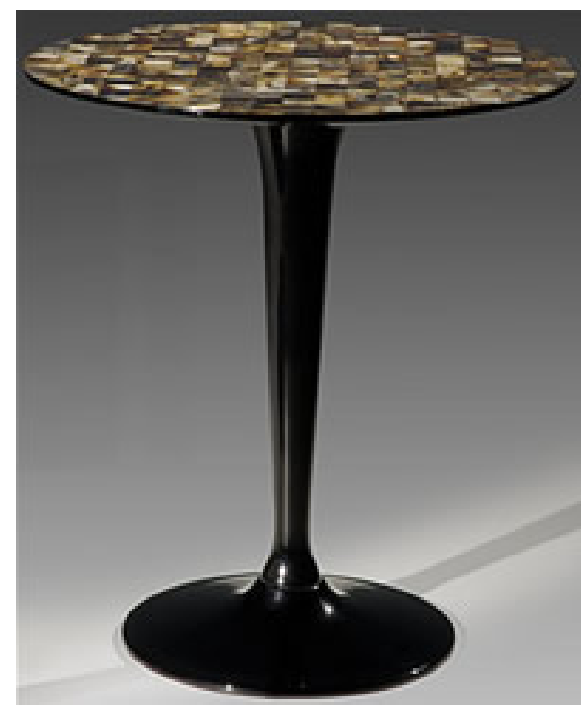

Figura 7 - Mesa decorada com pastilhas oriundas de chifres de boi. ${ }^{5}$

\section{DE SIMPATIAS À COMÉDIA}

$\mathrm{Na}$ Feira do Ver-o-Peso encontram-se dois vendedores de produtos de origem animal e vegetal. Ao perguntar sobre chifres, ofereceram essências para afastar chifres, referindo-se jocosamente à traição. Estes desenvolveram toda uma estratégia teatral de venda, compondo um ritual para explicar a qualidade dos seus produtos e a forma de usar. RR vendia um perfume amarelado com um rótulo impresso que diz: "Perfume Afasta Chifre". O seu colega, da barraca ao lado, oferecia tanto a essencia vendida pelo primeiro como um sabonete com as seguintes indicações:

"Sabonete natural. Indicações: para afastar todos os maus fluidos do chifre. Afasta chifre. Rasta (raspa?) de chifre de boi toto (???), folha de amansa e essências. Afasta chifre". No verso do mesmo sabonete: "Setor de ervas medicinais do Ver-o-Peso. Banca do João, n. 75. 
Comércio. Belém, Pará. Fone: 8188

3484. Ligue e faça o seu pedido”.

Para fazer marketing da qualidade do produto, contou uma longa estória que enfatizava ser verdadeira, mas com um tom de comédia que provocava mais hilaridade do que credibilidade. Segundo ele, todos os feirantes daquele entreposto utilizavam o produto e todos tinham obtido sucesso, à excessão de um que teria declinado do convite e fora traído pela esposa. Agravava a comédia narrando que a mesma havia engravidado do amante, o que teria provocado depressão no marido que vivia pelos cantos da Feira, a lamentar não ter confiado no produto.

A estória que usava como marketing, acrescentou um ritual demonstrando o uso da essência "Afasta chifre", pegando uma garrafa plástica PET, cheia d'água, recomendando que se diluissem algumas gotas do perfume e se lhes aspergisse na frente da casa, comércio ou local que se pretendesse exorcisar das possibilidades de traição ou para evitar que pessoas traídas se aproximassem do ambiente. O importante, segundo ele, era afastar a energia negativa que este tipo de malefício traz.

Outra pista seguida foi a pesquisa pela internet, onde encontram-se bares fazendo referência aos cornos. O Bar dos cornos, com endereço em São Paulo, assume o caráter pornográfico, alertando para que material deste teor não se encontra exposto no blog. ${ }^{6} \mathrm{O}$ proprietário assumiu a identidade de traído, trajando um chapéu com dois chifres que the teria sido deixado por um cliente, embora a sua companheira, coproprietária, em um vídeo disponível no mesmo blog desminta a versão da traíção. O fato é que ele não é o único bar com este tema no país, sendo muito conhecido o Bar do Corno Velho, em Aracaju, estado de Sergipe e outros conforme demonstra o Quadro 2.

Os usos destas representações para efeito de descontração podem ser incluídos nos usos terapêuticos, em que pese haver referência ao uso deste material com receitas para curar doenças em diversas partes do mundo (Costa Neto 2005).

A jocosidade se reproduz também em cartazes em locais públicos, para choques de caminhões e nos sites da internet, conforme se pode depreender da lista elaborada no Quadro 3.

Ainda fazendo render o aspecto jocoso, relembrando o Código filipino (1870), pesquisa nos sites da internet permitiu identificar uma lista de 93 tipos de traídos que se expressam conforme no Quadro 4.

Outra forma de manifestação jocosa é a atribuição de nomes a bancos de praças públicas como locais de encontro de traídos, como o Banco dos Cornos, na Praça da Ilha de Mosqueiro, em Belém, aumentando a gama de gozações e escárnio que se faz desta categoria.

\section{SIMPATIAS E BRUXARIAS}

Estão disponíveis em sites da internet receitas de simpatias para afastar a traição, ${ }^{7}$ utilizando chifres de bovinos, e de outros animais. Apenas a título de exemplo, listamos e comentamos alguns deles, como aquele recomendado para acabar com a insônia: 
Quadro 2

Estabelecimentos com referência aos cornos

\begin{tabular}{|l|l|l|}
\hline Nome do estabelecimento & \multicolumn{1}{|c|}{ Localização } & \multicolumn{1}{|c|}{ Endereço eletrônico } \\
\hline $\begin{array}{l}\text { Toquinho Bar e Lanche } \\
\text { Bar do corno }\end{array}$ & Pinheiros/SP & $\begin{array}{l}\text { http://pinheiros. } \\
\text { agenciacomunitaria. } \\
\text { org.br/2011/09/14/ } \\
\text { proprietarios-do-bar-do- } \\
\text { corno-alertam-bebida-nao- } \\
\text { e-remedio/ }\end{array}$ \\
\hline Recanto Nordestino & $\begin{array}{l}\text { Rua General Mac Artur, } \\
865, \text { Jaguaré, São Paulo, SP. }\end{array}$ & $\begin{array}{l}\text { http://www.guiadasemana. } \\
\text { com.br/sao-paulo/noite/ } \\
\text { bares/recanto-nordestino- } \\
\text { bar-dos-cornos }\end{array}$ \\
\hline $\begin{array}{l}\text { Bar e Restaurante Corno } \\
\text { Velho }\end{array}$ & $\begin{array}{l}\text { Rua Alu Campos, 5 Ara- } \\
\text { caju SE Tel: (79)32430287 }\end{array}$ & $\begin{array}{l}\text { http://www.restaurante- } \\
\text { cornovelho.com.br/ }\end{array}$ \\
\hline Bar do Corno & $\begin{array}{l}\text { Rua Dalva de Oliveira, 202 } \\
\text { - Carapicuíba, SP }\end{array}$ & $\begin{array}{l}\text { http://br.kekanto.com/ } \\
\text { biz/bar-do-corno }\end{array}$ \\
\hline
\end{tabular}

Quadro 3

Ditado com referência aos chifres

\begin{tabular}{|c|c|}
\hline Ditado & Fonte \\
\hline Sorria, você está sendo chifrado! & $\begin{array}{l}\text { http://www.ciadosbotecos. } \\
\text { com/2010/01/bar-dos-cornos-jaguare. } \\
\text { html }\end{array}$ \\
\hline $\begin{array}{l}\text { Chifre não existe... isso é coisa que } \\
\text { puseram na sua cabeça! }\end{array}$ & $\begin{array}{l}\text { http://www.ciadosbotecos. } \\
\text { com/2010/01/bar-dos-cornos-jaguare. } \\
\text { html }\end{array}$ \\
\hline O que leva homem para a frente é chifre! & $\begin{array}{l}\text { Ditado popular comum em áreas de cria- } \\
\text { ção agropecuária. }\end{array}$ \\
\hline $\begin{array}{l}\text { Se o diabo fosse sabido não tinha chifre } \\
\text { nem rabo }\end{array}$ & Ditado popular. Stanislaw Ponte Preta \\
\hline $\begin{array}{l}\text { Se a mulher soltar o rabo o homem leva } \\
\text { chifre }\end{array}$ & $\begin{array}{l}\text { Ditado popular ilustrado com figura de } \\
\text { duplo sentido. }\end{array}$ \\
\hline
\end{tabular}




\section{Quadro 4}

Os vários tipos de corno do Brasil

\begin{tabular}{|c|c|c|}
\hline $\mathrm{N}^{\mathrm{o}}$ & Tipo de corno & Explicação \\
\hline 1 & 7 de setembro & Aquele que a mulher só da bandeira. \\
\hline 2 & Abelha & Aquele que vai para rua fazer cera e depois volta cheio de mel \\
\hline 3 & Agressivo & Quando sabe, bate na mulher. \\
\hline 4 & Ambulância & $\begin{array}{l}\text { Aquele que quando vê a mulher com outro sai gritando: } \\
\text { uau! Uau! Uau! }\end{array}$ \\
\hline 5 & Amnésia & Quando bebe esquece que é corno. \\
\hline 6 & Artista & Acha que levar chifre é uma arte. \\
\hline 7 & Assumido & Assume os chifres e azar para quem se importa \\
\hline 8 & Ateu & Aquele que leva chifre e não acredita que é corno. \\
\hline \multirow[t]{2}{*}{9} & \multirow[t]{2}{*}{ Atleta } & $\begin{array}{l}\text { Enquanto ele sai para jogar futebol, o Ricardão chega para } \\
\text { encher a bola. }\end{array}$ \\
\hline & & É aquele que quando vê a mulher com outro sai correndo \\
\hline 10 & Atrasado & Aquele que é sempre o último a saber que é um. \\
\hline 11 & Atrevido & Aquele que se mete na conversa da mulher com o Ricardão. \\
\hline 12 & Azulejo & Baixinho, quadrado e liso. \\
\hline 13 & Babaca & Aquele que acredita em tudo que a mulher diz. \\
\hline 14 & Banana & A mulher vai embora e deixa uma penca de filhos. \\
\hline 15 & Bateria & O que fica dizendo: “vou tomar uma solução!". \\
\hline 16 & Bavaria & Aquele que divide a mulher com os amigos. \\
\hline 17 & Bondoso & Aquele que perdoa sempre as fugas da mulher. \\
\hline 18 & Brahma & Aquele que pensa que é o número 1. \\
\hline 19 & Bravo & Aquele que quando chamado de corno quer brigar. \\
\hline 20 & Brincalhão & $\begin{array}{l}\text { Aquele que leva chifre o ano inteiro e no carnaval sai fan- } \\
\text { tasiado de Ricardão. }\end{array}$ \\
\hline 21 & Burro & Aquele que quando é chamado de corno, fica sem entender. \\
\hline 22 & Caçador & Aquele que vive procurando quem lhe bote um par de chifres. \\
\hline 23 & Camarada & Aquele que ainda empresta dinheiro para o Ricardão. \\
\hline 24 & Caninha & Aquele que só chega em casa bêbado. \\
\hline 25 & Canoa & Aquele que é manobrado pela mulher. \\
\hline 26 & Carrapato & Aquele que vive grudado na mulher tentando evitar o chifre. \\
\hline 27 & Cebola & Aquele que quando vê a mulher com outro chora \\
\hline 28 & Cético & Quando vê a mulher com o outro não acredita. \\
\hline 29 & Cheguei & $\begin{array}{l}\text { Aquele que quando chega em casa grita bem alto: "amor, } \\
\text { cheguei!" }\end{array}$ \\
\hline 30 & Churrasco & Aquele que bota a mão no fogo pela mulher \\
\hline
\end{tabular}




\begin{tabular}{|c|c|c|}
\hline 31 & Cigano & $\begin{array}{l}\text { Aquele que toda vez que leva chifre, muda de bairro e diz } \\
\text { para os vizinhos que veio de São Paulo. }\end{array}$ \\
\hline 32 & Conformado & Aquele que acha que nasceu para ser corno. \\
\hline 33 & Corretor & $\begin{array}{l}\text { Aquele que a mulher só vive com ele porque não tem onde } \\
\text { morar e ele aceita. }\end{array}$ \\
\hline 34 & Crente & Aquele que sempre crê que só entra no céu quem tem chifre. \\
\hline 35 & Cururu & Quando vê a mulher com outro fica todo inchado \\
\hline 36 & Cuscuz & Aquele que vê e abafa. \\
\hline 37 & De recado & Aquele que ainda leva bilhete da mulher para o Ricardão. \\
\hline 38 & Denorex & Aquele que não parece, mas é. \\
\hline 39 & Descarado & Aquele que leva chifre e ainda sai desfilando com a mulher. \\
\hline 40 & Desconfiado & $\begin{array}{l}\text { Aquele que quando chega em casa procura o Ricardão até } \\
\text { debaixo da cama. }\end{array}$ \\
\hline 41 & Desinformado & Ele é o último a saber. \\
\hline 42 & Detetive & Aquele que segue a mulher dos cornos e esquece-se da dele. \\
\hline 43 & Dinossauro & É aquele que já tem chifres há milhões de anos \\
\hline 44 & Educado & $\begin{array}{l}\text { Aquele que aprendeu com o pai e nunca deixa de cumpri- } \\
\text { mentar o Ricardão. }\end{array}$ \\
\hline 45 & Elétrico & É aquele que quando avisam que ele é corno diz: tô ligado \\
\hline 46 & Familiar & Aquele que leva chifre de parente. \\
\hline 47 & Famoso & Aquele que por onde passa é reconhecido como tal. \\
\hline 48 & Fofoqueiro & Aquele que leva chifre e sai contando para todo mundo. \\
\hline 49 & Fracassado & Aquele que é doido para ser corno e a mulher não ajuda. \\
\hline 50 & Frio ou Geladeira & É aquele que leva chifre e não esquenta \\
\hline 51 & Galo & $\begin{array}{l}\text { Aquele que tem chifre até nos pés, a mulher é uma galinha e } \\
\text { ele ainda vive cantando. }\end{array}$ \\
\hline 52 & Granja & O que dá casa e comida mas é os outros que comem. \\
\hline 53 & Hereditário & A tradição de ser corno passa de pai para filho \\
\hline 54 & Homicida & Aquele que quando sabe que é corno, tenta se matar \\
\hline 55 & Indeciso & Aquele que quando descobre que é não sabe o que faz. \\
\hline 56 & Inflação & A cada dia que passa o chifre aumenta. \\
\hline 57 & Inocente & Aquele que é corno e não sabe. \\
\hline 58 & Ioiô & É aquele que vai e volta \\
\hline 59 & Jiboia & O que dorme entre as pernas da mulher. \\
\hline \multirow{2}{*}{60} & \multirow{2}{*}{ Manso } & O que vê a mulher com o outro e só balança a cabeça. \\
\hline & & É aquele que evita qualquer confusão com o Ricardão \\
\hline 62 & Masoquista & Aquele que leva chifre e não larga a mulher. \\
\hline 63 & Matemático (ou 120) & É aquele que fraga a mulher num 69 e vai para o bar tomar 51 \\
\hline
\end{tabular}




\begin{tabular}{|l|l|l|}
\hline 64 & Medroso & Aquele que fica esperando o Ricardão ir embora. \\
\hline 65 & Mentiroso & Aquele que mente sempre para defender a mulher \\
\hline 66 & Misterioso & Aquele que esconde a mulher para ninguém ver \\
\hline 67 & Morcego & Aquele que só aparece à noite para chupar. \\
\hline 68 & Pai de santo & Aquele que chega em casa e tira o caboclo de cima da mulher. \\
\hline 69 & Papai Noel & Aquele que leva chifres, vai embora e volta por causa das crianças. \\
\hline 70 & Penoso & Aquele que tem pena de deixar a mulher. \\
\hline 71 & Pescador & Aquele que prefere segurar a vara. \\
\hline 72 & Pilatos & Aquele que quando sabe lava as mãos. \\
\hline 73 & Político & O que promete: “eu vou matar esse cara!”; mas nunca cumpre. \\
\hline 74 & Porco & Aquele que só come resto. \\
\hline 75 & Preguiça & Aquele que só chega atrasado e diz: “eu ainda te pego”. \\
\hline 76 & Prevenido & O que liga para a esposa antes de ir para casa. \\
\hline 77 & Radar & Aquele que sabe que é corno à distância. \\
\hline 78 & Religioso & Aquele que acha que a mulher dá para fazer caridade. \\
\hline 79 & Repetente & Aquele que troca de mulher, mas continua corno. \\
\hline 80 & Revoltado & Aquele que não aceita a realidade \\
\hline 81 & Salário & Baixinho e só comparece uma vez por mês. \\
\hline 82 & Salsa e merengue & Quando chega de repente no quarto se espanta: Êpa, um dois, três! \\
\hline 83 & São Tomé & Aquele que só acredita quando ver. \\
\hline 84 & Secreto & Aquele que está em nosso meio, mas ninguém sabe. \\
\hline 85 & Sem vergonha & Aquele que a mulher bota chifre até com sapatão. \\
\hline 86 & Socialista & Aquele que não se importa em dividir com os outros. \\
\hline 87 & Surdo & Aquele que não dá ouvidos a ninguém, sua mulher é uma santa. \\
\hline 88 & Teimoso & Aquele que leva chifre da mulher e da amante. \\
\hline 89 & Temporal & Aquele que vive dando tempo para deixar a mulher. \\
\hline 90 & Terremoto & Quando vê a mulher com o outro começa a tremer. \\
\hline 91 & Valente & Aquele que não sabe, mas quando fica sabendo vira uma fera. \\
\hline 92 & Vingador & Aquele que para se vingar dá o rabo na frente da mulher. \\
\hline 93 & Xuxa & O que não larga a mulher por causa dos baixinhos \\
\hline
\end{tabular}

Fonte: Conheça 10 tipos de cornos brasileiros. Disponível em http://listas.terra.com. br/humor/158-conheca-10-tipos-de-cornos-brasileiro. Acessado em 18/12/2012; 93 Tipos de Corno. Disponível em http:/ / www.juraemprosaeverso.com.br/HumorDoPovoBrasileiro/ 93TiposdeCornos.htm. Acessado em 18/12/2012. 
"Separa os componentes conforme a relação: Um chifre de boi. Ponteiro de ferro. Palha da costa. Pedrinhas polidas. Adquira um pequeno chifre de boi, e com um ponteiro de ferro em brasa faça na boca do chifre vinte e um furos. Arranje palha da costa e faça uma trança bem fina, sempre no sentido da esquerda para a direita e vá enfiando nos furos, no final dê um laço.

Pegue o chifre e amarre-o embaixo de sua cama, no lado que você dorme; no dia que você sentir insônia, procure pensar em uma planície com bastante gado e reze para Seu Manuel Boiadeiro levar a insônia para bem longe, livrando-a da perturbação que está sentindo.

$\mathrm{E}$ todas às vezes que você for atendido(a), coloque dentro do chifre uma pedrinha polida. Bons sonhos! SALVE SEU BOIADEIRO! $!^{8}$

O que se verifica na simpatia acima é uma combinação do uso de material consagrado no culto afro-brasileiro, como a palha da costa, o chifre de boi, pedrinhas polidas associadas a um exercício de relaxamento e à invocação de um santo popular, o Seu Manoel Boiadeiro. O que ressalta o uso do chifre é não apenas a extremidade do bovino utilizada na simpatia, mas também a invocação de um personagem de profissão ligada ao apascentamento dos bovinos.

Pelo site de busca foi encontrada a seguinte simpatia recomendada para a proteção das casas: "1 chifre de boi , 7 dentes de alho e vinho moscatel. Colocar os dentes dentro do chifre, encher o chifre com o vinho moscatel. Uma vez por mês trocar o vinho, colocar o vinho retirado em um matinho. Pedir proteção a Oxosse [sid]".
A combinação neste caso é feita com dentes de alho que se assemelham na forma ao quarto crescente, e devem ser em número de sete, número cabalístico ao qual se atribui o caráter de totalidade (Chevalier \& Gheerbrant 2012: 826), sofisticando-se a fórmula com o acréscimo de vinho moscatel e apelação feita, neste caso, a entidade do culto africano, Oxossi, considerado senhor das florestas.

Pelo mesmo processo de busca eletrônica, encontra-se a simpatia com variante de chifre de veado, para segurar a pessoa amada. Entram, pois como ingredientes, forma de preparo e modo de usar:

"Rapas [sic] de chifre de veado, um ímã redondo, uma cuia (coité), um pouco de mel, vinho branco, papel de pão, uma vela pequena. Coloque o nome de quem você gosta escrito em um papel de pão; escreva o seu nome por cima do dele(a), formando uma cruz e coloque no fundo da coité; ponha o ímã em cima, semeie a raspa [de chifre] de veado e cubra com mel; coloque também um pouco de vinho. Se você mora em apartamento, coloque embaixo do tanque de lavar roupa por uma semana. Se der formiga, não importe, mas se você mora em casa, coloque também debaixo do tanque, mas do lado de fora, no quintal, acenda uma vela pequena somente no dia que você fizer esta simpatia.

Ofereça esta imantação para Dona Maria Cigana e boa sorte.

Obs.: Se você obtiver bons resultados, espere passar um mês mais ou menos e acenda mais um maço de velas para quem você ofereceu a imantação. SUCESSOS!" ${ }^{\prime 10}$ 
Neste caso, o chifre entra como componente em raspas ou pequenos pedaços, sem nenhuma referencia específica ao seu formato. Pelo já escrito, podemos deduzir que a força desta parte do animal entra na composição desta mandinga pelo seu caráter lúbrico, sexual, ligado às forças genésicas.

\section{CONSIDERAÇÕES FINAIS}

O repertório de significados dos chifres de bovídeos é merecedor de pesquisa que possa lhe explorar a amplitude e romper com a predominância da interpretação jocosa que se faz na cultura latina das representações encontradas em diversas sociedades. A dureza e resistência do material de que é constituído, o formato cônico, de representação ambígua de masculinidade e feminilidade, de fecundidade, fertilidade, força, poder, agressividade, luminosidade, comunicação com o divino, explicam parcialmente o uso variado confirmado na história da humanidade em todos os quadrantes. Estes atributos justificam os seus usos no plano imaterial, seja como componente principal, seja como secundário, nas simpatias, mandingas, feitiços e bruxarias.

A inventividade dos artistas, sejam eles ingênuos ou formados em escolas de reconhecido valor estético, recorre frequentemente à matéria prima de valor semiótico para suas obras, e o chifre é seguramente um deles. $\mathrm{O}$ seu formato de meia lua, de raio, de braço da cruz, de falo, de caráter ascendente, pontiagudo ou de receptáculo inspira os simbolismos acionados na magia e nas obras de caráter estético.

\section{NOTAS}

1 Código Filipino, 1870, Livro V, Titulo XXVI, item 9. Disponível em http://www1. ci.uc.pt/ihti/proj/ filipinas/15p1177.htm. Acessado em 15/02/2013

${ }^{2}$ Disponível em http://letras.mus.br/ednardo/301661/. Acessado em 10/06/2013.

3 Em poucos minutos o Sr. Lourival Farias Dias disse o seu nome, fez um breve relato de sua trajetória comercial. Antes tinha um bar que denominou de bar do Camarão, em referencia ao apelido pelo qual era conhecido. Este apelativo provocava confusão porque ele não vendia camarões e por isso ele teria trocado o nome para Bar do Louro, outro apelido que faz referencia ao seu nome original, Lourival.

${ }^{4} \mathrm{O}$ primeiro contato foi feito no dia 21/10/2012, embora a barraca já tivesse sido identificada antes. $O$ ponto comercial ficava do lado direito da estrada, no sentido, Belém Capanema, tendo se deslocado para o lado esquerdo da mesma. Houve outros momentos de entrevista ao longo dos meses até fevereiro de 2013.

${ }^{5}$ Inside móveis, disponível em http:/ / www.insidemoveis.com.br/index.php?option $=\mathrm{com}$ content\&task $=$ view\&id $=38 \&$ Itemid $=54$. Acessado em 22/10/2012.

${ }^{6}$ Disponível em http://www.ciadosbotecos. com/2010/01/bar-dos-cornos-jaguare.html. Acessado em 18/12/2012.

${ }^{7}$ Disponível em http://bruxasdoamor.blogspot. com.br/2012/01/simpatia-por-um-amor-divulgada-no.html. Acessado em 10/06/2013.

${ }^{8}$ Disponível em http://maemartadeoba. com.br/seguro/simpatiaimantadas.htm. Acessado em 22/12/2012

9 Disponível em http://books.google.com. $\mathrm{br} /$ books?id $=z P 6 g O I o z Y M U C \& p g=P A 5$ $8 \& \mathrm{lpg}=\mathrm{PA} 58 \& \mathrm{dq}=$ mandingas $+\mathrm{com}+\mathrm{chif}$ res\&source $=$ bl\&ots $=$ rda0UFSM0r\&sig $=\mathrm{v}$ 
1EvUTKjTCheNWmA_2jnmb7bcB4\&hl $=$ pt-BR\&sa $=$ X\&ei $=$ bSiFUNeFIZKi8QT ZooGICg\&sqi $=2 \& v e d=0$ CEcQ6AEwBQ $\#_{\mathrm{v}}=$ onepage $\& \mathrm{q}=$ mandingas $\% 20 \mathrm{com} \% 20$ chifres\&f=false. Acessado em 22/10/2012.

${ }^{10}$ Disponível em http://maemartadeoba. com.br/seguro/simpatiaimantadas.htm. Acessado em 22/12/2012.

\section{REFERÊNCIAS}

A Bíblia Sagrada 1995. São Paulo: Edições Loyola.

Câmara, W. de S. 2008. Os chifres de Moisés. Disponível em http://linguahebraica. blogspot.com/2008/09/hebraico-raiz-dapalavra-querenqaran.html. Acessado em 09/05/2013.

Chevalier, J. e A. Gheerbrant. 2012. Dicionário de símbolos. Mitos, sonhos, costumes, gestos, formas, figuras, cores, números. $26^{\mathrm{a}}$ ed. Rio de Janeiro: José Olympio Editora.

Costa Neto, E. M. 2005. Animal-based medicines: biological prospection and the sustainable use of zootherapeutic resources. Anais da Academia Brasileira de Ciências 77(1): 33-43.

Cunha, A. G. da. 2010. Dicionário Etmológico da Limgua Portuguesa. 4a.ed. Rio de Janeiro, Lexikon.

Ferreira, A. B. de H. 2000. Novo Dicionário da Lingua Portuguesa. $1^{\text {a }}$ Ed. Rio de Janeiro: Nova Fronteira.

Mariguela, M. 2010. Frend e o Moisés de Michelangelo. Psicanálise e filosofia. Disponível em http://www.google.com.br/ imgres?imgurl=http: $/ /$ marciomariguela. files.wordpress.com/2010/04/moises4. jpg\&imgrefurl=http:/ / marciomariguela. wordpress.com/2010/04/22/freud-e-omoises-de michelangelo $/ \& \mathrm{~h}=436 \& \mathrm{w}=3$ 40\&sz $=20 \&$ tbnid $=$ ssD79Wey7RPClM: $\&$ $\mathrm{tbnh}=92 \& \mathrm{tbnw}=72 \&$ zoom $=1 \& u s g=$
ZWnKFoQHk93mEXCRu_C7-EJhfbs= $\&$ docid $=$ cAqng4JFJFRwmM\&hl=pt-BR \&sa=X\&ei=IJuKUdugN5C00AHRg4G AAg\&ved=0CEAQ9QEwBA\&dur=203. Postado em 22 de abril de 2010. Acessado em 08/05/2013.

Porto-Gonçalves, C. W. 2005. Os (Des) caminhos do Meio Ambiente. Vol. 1 12a . ed. São Paulo: Contexto.

Nobre, D. 2012. Vou botar teu nome na macumba. Disponível em http://letras. mus.br/dudu-nobre/107751/ Acessado em 22/10/2012.

Paes Loureiro, J. de J. 1995. Cultura Amarônica. Uma poética do imaginário. Belém, CEJUP.

Ronecker, J-P. 1997. O simbolismo animal. Mitos, crencas, lendas, arquétipos, folclore, imaginário. São Paulo: Paulus.

Sant'Anna, S. M. 2006. A boa morte e o bom morrer. Culto, doutrina, iconografia e irmandades mineiras (1721 a 1822). Dissertação de Mestrado. Departamento de Pós Graduação em História, Faculdade de Filosofia e Ciências Humanas, Universidade Federal de Minas Gerais, Belo Horizonte/MG, Brasil.

Toma, M. 2013. História, legislação e degredo em Portugal. Disponível em http://www. tjrs.jus.br/export/poder_judiciario/historia/memorial_do_poder_judiciario/ memorial_judiciario_gaucho/revista_ justica_e_historia/issn_16765834/v5n10/ doc/2_Maristela_Toma.pdf. Acessado em 15/02/2013.

Recebido em 30/05/2013.

Aprovado em 31/07/2013. 